\title{
COVID-19 cases and testing in 53 prison systems
}

\author{
Katherine Lemasters ${ }^{1}$, Erin McCauley ${ }^{2}$, Kathryn Nowotny ${ }^{3}$ and Lauren Brinkley-Rubinstein ${ }^{4,5^{*}}$ (D)
}

\begin{abstract}
Background: COVID-19 has entered United States prison systems at alarming rates. Disparities in social and structural determinants of health disproportionately affect those experiencing incarceration, making them more vulnerable to COVID-19. Additionally, prisons are sites of congregate living, making it impossible to practice social distancing, and most prisons have relied only on incremental measures to reduce risk and spread of COVID-19. To more fully understand the impact that COVID-19 is having on incarcerated populations, it is critical to have systematic data on testing, test positivity, cases, and case fatality. Using data from the COVID Prison Project, we present data on 53 prison systems COVID-19 testing, test positivity, case, and case fatality by state and compare these data with each state's general population. We do this for the early stages of the pandemic, utilizing data through July 15, 2020.

Results: Many states are not reporting full information on COVID testing with some also not reporting on case fatality. Among those reporting data, there is a wide variation between testing, test positivity, and case rates within prison systems and as compared to the general population. However, when more tests are deployed more cases are identified with the majority of state prisons having higher case rates than their general population.

Conclusions: These findings underscore the need for the implementation and study of COVID-19 mitigation and surveillance strategies to flatten the COVID-19 curve in prisons across the country. We call for future research to build on these data from the COVID Prison Project to protect the health of our nations' often forgotten residents.
\end{abstract}

Keywords: Mass incarceration, COVID-19, health disparities

\section{Introduction}

The United States (US) leads the world in both COVID19 infections and mass incarceration. In the US, as of July 15, 2020, there are 3,475,698 infections and 136,649 deaths in the US (Johns Hopkins University, 2020). While the US has only $4 \%$ of the world's population, it has a quarter of the world's COVID-19 infections and deaths (Johns Hopkins University, 2020; The Atlantic, 2020). Simultaneously, the US has over a quarter of the

\footnotetext{
* Correspondence: Lauren_Brinkley@med.unc.edu

${ }^{4}$ Center for Health Equity Research, University of North Carolina at Chapel Hill, 333 S. Columbia Street, Chapel Hill, NC 27559, USA

${ }^{5}$ Department of Social Medicine, University of North Carolina at Chapel Hill, 333 S. Columbia Street, Chapel Hill, NC 27559, USA

Full list of author information is available at the end of the article
}

world's incarcerated population (Wagner \& Bertram, 2020). Yet, these two public health emergencies do not exist in silos. COVID-19 has entered our country's prisons, jails, and communities most impacted by mass incarceration at astounding rates (The COVID Prison Project, 2020; The Marshall Project, 2020). In fact, jails and prisons have become epicenters of the pandemic with nine of the ten largest single site outbreaks occurring in correctional settings (The COVID Prison Project, 2020).

The confluence of mass incarceration and COVID-19 is not a coincidence. Both socioeconomic status and racism are fundamental causes of health inequities and drivers of mass incarceration (Link \& Phelan, 1995; Phelan \& Link, 2015). Disparities in social and structural 
determinants of health disproportionately impact racial minorities, those experiencing homelessness, and persons with substance use disorders or mental illness, all of whom are more likely to be incarcerated due to mass incarceration's roots in racial inequities and discriminatory practices (Akiyama, Spaulding, \& Rich, 2020; Garcia \& Sharif, 2015). People who are incarcerated also have a higher burden of poor health outcomes making them more likely to suffer severely from COVID-19 (Akiyama et al., 2020). Carceral settings themselves also amplify the risk of COVID with common prevention activities like social distancing being impossible to engage in due to dormitory style living conditions or overcrowding (Akiyama et al., 2020). In addition, the communities that people return home to and come into prisons from also bear a disproportionate burden of COVID-19. Black Americans are both overrepresented in the criminal legal system and are more likely to live in areas with higher poverty rates, have limited health care access, and have higher rates of jobs in service industries where they are less able to work from home, which increases exposure to COVID-19 (Gould \& Shierholz, 2020; Laurencin \& McClinton, 2020).

Policymakers, advocates, and academics have called for decarceration, specifically by increasing the number of compassionate releases, eliminating cash bail, and releasing those imprisoned for low-level crimes and misdemeanors (Akiyama et al., 2020; Nowotny, Bailey, Omori, \& Brinkley-Rubinstein, 2020). However, prisons have yet to do this, instead relying on incremental measures such as suspending family and legal visits, distributing masks, and reducing the amount of time that people can spend recreating (Widra \& Hayre, 2020). On average, prisons have only reduced their populations by $5 \%$ (Widra \& Wagner, 2020). In the meantime, outbreaks have continued to occur in prisons throughout the country.

Given these outbreaks and the vulnerability of the imprisoned population, it is important that we comprehensively document the prevalence of COVID-19 within prisons. To do this, it is critical that we have systematic data on testing, test positivity, cases, and case fatality. While this is a pressing national issue, these data must be assessed at the state level as each state's Department of Corrections collects data independently and independently determines their COVID policies. Additionally, each state's general population has a different prevalence of COVID-19 infection and differing COVID policy (e.g., mandatory masks; stay-at-home orders), making the context surrounding these data unique to each state. In this paper, we present testing, infection, and fatality data by state to document the effect of COVID-19 on incarcerated populations in the early stages of the pandemic. To do this, we use novel data from the COVID Prison Project (CPP) on each state prison's COVID data. We call for future research to build on CPP data to protect the health of our nations' often forgotten residents.

\section{Methods \\ COVID-19 prison data}

For COVD-19 data in prisons, we used publicly accessible data from the (CPP) (The COVID Prison Project, 2020). The CPP publishes a daily aggregate dataset examining COVID-19 in correctional facilities, including data on the number of tests, the number of confirmed positive cases, and mortality, among other factors, due to COVID-19 among correctional staff and incarcerated individuals. The data are aggregated by CPP based on public reports by prison systems. Each day, counts were extracted from Department of Corrections websites and supplemented with information from media reports and press releases. In total the CPP collects daily data for 53 prison systems (all 50 states, Puerto Rico, the Federal Bureau of Prisons, and Immigration and Customs Enforcement (ICE).

\section{Prison population data}

For prison population data, we used data collected by the Vera Institute of Justice (Vera Institute of Justice, 2020). Prison population counts were collected during the first quarter of 2020, and largely capture the changes in population size due to COVID-19. When possible, we use the most recent count (collected on April 30th / May 1st, 2020). For states without data from this most recent wave, we use the second most recent count (December 31st for Illinois, Maryland, Minnesota, New Mexico and Virginia; and March 31st for Montana, South Dakota, Tennessee, and Washington). For ICE, we use the currently detained population as of July 11th 2020 (United States Immigration and Customs Enforcement, 2020). For Puerto Rico, we use data from the Bureau of Justice Statistics, last updated in 2012 (Bureau of Justice Statistics, 2012).

\section{General population data}

For general population COVID-19 counts, we used data for positive cases and fatalities from the Johns Hopkins Coronavirus Resource Center and data on testing numbers from the COVID Tracking Project (Johns Hopkins University, 2020; The Atlantic, 2020). For the general population count, we used data from The U.S. Census Bureau (United States Census Bureau, 2019). The U.S. Census Bureau collects annual population estimates by state in July of each year. This study uses the 2019 state population estimates to create rates for the general population. Data come from all 50 US states and Puerto Rico. COVID-19 cases were captured cumulatively and include active cases, recovered cases, and fatalities. COVID-19 tests and fatalities were also captured 
cumulatively. General population COVID-19 data on case numbers and fatalities are available through both the John Hopkins Coronavirus Resource Center and the COVID Tracking Project. As a sensitivity analysis we calculated rates using both sources and found similar patterns. Alternative tables using the COVID Tracking Project data on cases and fatalities are available by request.

\section{Analysis}

We calculated crude COVID-19 testing, case, and case fatality rates separately by state for both the prison and general population. We also calculated the test positivity (the percent of tests that are returned positive) in the prison population and general population by state. Data is presented at the state level due to large differences in both testing strategies and COVID-related policies in each state. The World Health Organization recommends that a test positivity rate between 3 and $12 \%$ indicates adequate testing coverage (World Health Organization, 2020). This is the standard that we use.

\section{Results}

As of July 15, 2020, 10 states and Puerto Rico were reporting no testing information (Table 1). Of those that report testing numbers, testing varies widely with Hawaii testing 6 per 1000 people who are incarcerated and Minnesota testing 1531 per 1000 people who are incarcerated, indicating an average of more than one test per incarcerated person. Maryland, Massachusetts, Michigan, Minnesota, Missouri, New Jersey, Rhode Island, Tennessee, Texas, Vermont, West Virginia, and Wisconsin have all administered more than 500 tests per 1000 incarcerated people, with Maryland, Massachusetts, Michigan, Minnesota, and Vermont having all administered more than one test per incarcerated person--indicating a universal testing effort in which all people currently incarcerated have had access to a COVID-19 test. The majority of prison systems have tested a higher proportion of their incarcerated population than the state's general population. However, eleven prison systems are still testing fewer incarcerated people per 1000 than their state's general population.

\section{Testing positivity}

Among those tested, test positivity varied by state from 0 to $42 \%$. Systems with the highest test positivity have, on average, tested a small proportion of their incarcerated population. For example, Louisiana has tested 55 per 1000 incarcerated people and has a test positivity of 41\%. Similarly, Idaho has tested 180 per 1000 incarcerated people and has a test positivity of $42 \%$. Test positivity is, on average, higher in prison systems than the general population, but some prison systems have lower test positivity than their general population. This includes states with recent outbreaks in their general population (e.g., Arizona, Florida), those testing very few people who are incarcerated (e.g., Nebraska), and those conducting mass testing (e.g., Minnesota).

\section{Case rates and case fatality rates in prisons and the general population}

Thirty-four of the prison systems have case rates per 1000 that are higher than the general population. New Jersey has the highest cases per 1000 incarcerated people at 159/1000. Among those detecting more than 100 cases per 1000 incarcerated people (Arkansas, Michigan, New Jersey, Ohio, Tennessee), all have tested a high proportion of their population. By comparison, the highest case rate in the general population is in New York with 21 per 1000 testing positive. Six states (Arkansas, Connecticut, Michigan, New Jersey, Ohio, and Tennessee) have detected over 100 cases per 1000 greater than their state's general population. For instance, New Jersey has detected 159 cases per 1000 incarcerated people and 20 cases per 1000 in the general population, resulting in a disparity of 139 absolute cases per 1000 individuals between the general population and the population incarcerated in state prisons in New Jersey. Thirty-seven states are reporting case fatality data. Fatalities per 1000 cases range from zero in Hawaii, North Dakota, Rhode Island, South Dakota, and Utah to 11 deaths per 1000 cases in the Federal Bureau of Prisons.

\section{Discussion}

This analysis indicates that there was wide variation between testing and case rates in various prison systems and the general population in the early phases of the COVID-19 pandemic. Previous research has estimated national prevalence of various state and federal prison systems (Saloner, Parish, Ward, DiLaura, \& Dolovich, 2020). However, it is important to understand the COVID-19 pandemic and its impact on prison systems at a more granular level. For instance, when aggregating numbers at the national level, we are unable to differentiate between prison systems that are experiencing severe outbreaks versus those that have low case rates. This disguises important and time-sensitive impacts that COVID-19 is having on states and communities across the country and makes it harder to understand where the focus on attention and intervention should be. Additionally, our findings demonstrate that more often than not, more testing equals more cases identified. However, uneven testing rates across the states prevents the public health community from having a clear understanding of the extent of COVID-19 incidence in prison settings in several states. Nevertheless, even with uneven testing 
Table 1 COVID-19 Outcomes of Incarcerated People Compared to the General Population

\begin{tabular}{|c|c|c|c|c|c|c|c|c|}
\hline \multirow[t]{2}{*}{ State } & \multicolumn{2}{|c|}{ Tests per 1000} & \multicolumn{2}{|c|}{ Positive Cases per 1000} & \multicolumn{2}{|c|}{ Fatalities per 1000 Cases } & \multicolumn{2}{|c|}{ Test Positivity Rate (\%) } \\
\hline & $\begin{array}{l}\text { General } \\
\text { Population }\end{array}$ & $\begin{array}{l}\text { Prison } \\
\text { Population }\end{array}$ & $\begin{array}{l}\text { General } \\
\text { Population }\end{array}$ & $\begin{array}{l}\text { Prison } \\
\text { Population }\end{array}$ & $\begin{array}{l}\text { General } \\
\text { Population }\end{array}$ & $\begin{array}{l}\text { Prison } \\
\text { Population }\end{array}$ & $\begin{array}{l}\text { General } \\
\text { Population }\end{array}$ & $\begin{array}{l}\text { Prison } \\
\text { Population }\end{array}$ \\
\hline Alabama & 110 & 21 & 12 & 5 & 21 & 9 & 11 & 24 \\
\hline Alaska & 213 & 400 & 2 & 2 & 10 & & 1 & 0 \\
\hline Arizona & 101 & 109 & 18 & 14 & 19 & 2 & 18 & 13 \\
\hline Arkansas & 131 & 406 & 10 & 149 & 11 & & 8 & 37 \\
\hline California & 147 & 443 & 9 & 55 & 21 & 1 & 6 & 12 \\
\hline Colorado & 71 & 357 & 7 & 36 & 46 & 0 & 9 & 10 \\
\hline Connecticut & 169 & & 13 & 122 & 92 & 1 & 8 & \\
\hline Delaware & 147 & & 13 & 55 & 40 & 3 & 9 & \\
\hline Florida & 127 & 308 & 14 & 28 & 15 & 1 & 11 & 9 \\
\hline Georgia & 109 & & 12 & 15 & 24 & 3 & 11 & \\
\hline Hawaii & 69 & 6 & 1 & 0 & 17 & 0 & 1 & 0 \\
\hline Idaho & 75 & 180 & 7 & 76 & 9 & & 9 & 42 \\
\hline Illinois & 164 & 24 & 12 & 9 & 47 & 4 & 8 & 37 \\
\hline Indiana & 87 & 79 & 8 & 27 & 52 & 3 & 9 & 35 \\
\hline lowa & 123 & 450 & 12 & 25 & 21 & 0 & 9 & 6 \\
\hline Kansas & 82 & & 7 & 93 & 15 & 0 & 9 & \\
\hline Kentucky & 103 & & 5 & 29 & 31 & 1 & 5 & \\
\hline Louisiana & 215 & 55 & 18 & 22 & 41 & 2 & 8 & 41 \\
\hline Maine & 95 & 588 & 3 & 2 & 32 & & 3 & 0 \\
\hline Maryland & 112 & 1024 & 12 & 34 & 45 & 1 & 11 & 3 \\
\hline Massachusetts & 143 & 1010 & 16 & 54 & 74 & 2 & 11 & 5 \\
\hline Michigan & 137 & 1017 & 8 & 103 & 80 & 2 & 6 & 10 \\
\hline Minnesota & 140 & 1531 & 8 & 39 & 36 & 1 & 6 & 3 \\
\hline Mississippi & 120 & 15 & 13 & 5 & 33 & 1 & 11 & 31 \\
\hline Missouri & 84 & 618 & 5 & 10 & 37 & 0 & 6 & 2 \\
\hline Montana & 116 & 404 & 2 & 0 & 16 & & 2 & 0 \\
\hline Nebraska & 114 & 162 & 11 & 1 & 13 & & 10 & 1 \\
\hline Nevada & 118 & & 10 & 1 & 20 & & 8 & \\
\hline $\begin{array}{l}\text { New } \\
\text { Hampshire }\end{array}$ & 101 & 17 & 4 & 0 & 64 & & 4 & 2 \\
\hline New Jersey & 196 & 714 & 20 & 159 & 89 & 2 & 10 & 22 \\
\hline New Mexico & 205 & 218 & 8 & 24 & 35 & 1 & 4 & 11 \\
\hline New York & 249 & 99 & 21 & 13 & 80 & 3 & 8 & 13 \\
\hline North Carolina & 122 & 268 & 9 & 32 & 17 & 1 & 7 & 12 \\
\hline North Dakota & 166 & & 6 & 5 & 19 & 0 & 4 & \\
\hline Ohio & 91 & 346 & 6 & 105 & 44 & 2 & 7 & 30 \\
\hline Oklahoma & 113 & 164 & 6 & 0 & 19 & & 5 & 0 \\
\hline Oregon & 72 & 112 & 3 & 22 & 19 & 0 & 4 & 20 \\
\hline Pennsylvania & 76 & 154 & 8 & 6 & 68 & 4 & 10 & 4 \\
\hline Puerto Rico ${ }^{a}$ & 64 & & 3 & 0 & 16 & & 5 & \\
\hline Rhode Island & 166 & 701 & 17 & 10 & 56 & 0 & 10 & 1 \\
\hline South Carolina & 102 & & 12 & 31 & 16 & 1 & 12 & \\
\hline South Dakota & 106 & 33 & 9 & 1 & 15 & 0 & 8 & 3 \\
\hline
\end{tabular}


Table 1 COVID-19 Outcomes of Incarcerated People Compared to the General Population (Continued)

\begin{tabular}{|c|c|c|c|c|c|c|c|c|}
\hline \multirow[t]{2}{*}{ State } & \multicolumn{2}{|c|}{ Tests per 1000} & \multicolumn{2}{|c|}{ Positive Cases per 1000} & \multicolumn{2}{|c|}{ Fatalities per 1000 Cases } & \multicolumn{2}{|c|}{ Test Positivity Rate (\%) } \\
\hline & $\begin{array}{l}\text { General } \\
\text { Population }\end{array}$ & $\begin{array}{l}\text { Prison } \\
\text { Population }\end{array}$ & $\begin{array}{l}\text { General } \\
\text { Population }\end{array}$ & $\begin{array}{l}\text { Prison } \\
\text { Population }\end{array}$ & $\begin{array}{l}\text { General } \\
\text { Population }\end{array}$ & $\begin{array}{l}\text { Prison } \\
\text { Population }\end{array}$ & $\begin{array}{l}\text { General } \\
\text { Population }\end{array}$ & $\begin{array}{l}\text { Prison } \\
\text { Population }\end{array}$ \\
\hline Tennessee & 161 & 894 & 10 & 122 & 11 & 0 & 6 & 14 \\
\hline Texas & 91 & 912 & 10 & 80 & 12 & 1 & 11 & 9 \\
\hline Utah & 135 & 87 & 10 & 1 & 8 & 0 & 7 & 1 \\
\hline Vermont & 126 & 1031 & 2 & 34 & 42 & & 2 & 3 \\
\hline Virginia & 99 & & 9 & 42 & 27 & 1 & 9 & \\
\hline Washington & 94 & 156 & 6 & 15 & 33 & 1 & 6 & 9 \\
\hline West Virginia & 122 & 771 & 3 & 19 & 22 & & 2 & 2 \\
\hline Wisconsin & 125 & 1068 & 7 & 13 & 21 & & 6 & 1 \\
\hline Wyoming & 74 & & 3 & 0 & 11 & & 5 & \\
\hline BOP & & 172 & & 52 & & 11 & & 30 \\
\hline $\mathrm{ICE}^{\mathrm{b}}$ & & 607 & & 157 & & 1 & & 26 \\
\hline
\end{tabular}

${ }^{a}$ Puerto Rico general population data is from the same census source as all general population data; Puerto Rico prison population data is from The Bureau of Justice Statistics in 2012, available at: https://www.bjs.gov/index.cfm?ty=tp\&tid=144). The prison population in 2012 was 12,244.

${ }^{\mathrm{b}}$ Immigrantion and Customs Enforcement population data is available at: https://www.ice.gov/detention-management). The population as of July 11,2020 was 22,340 .

rates, the majority of states have a COVID-19 case rate that is higher than the state's general population.

The disparity in COVID-19 case rates between prisons and their surrounding general populations highlights the need for action. Decarceration must remain a priority as it is the most effective way to prevent COVID-19 in carceral settings. In concert, though, prison systems should be the focus of robust testing efforts and be provided the resources to develop and deploy long-term testing strategies. The Centers for Disease Control and Prevention has indicated that asymptomatic testing in prison settings is warranted (The Centers for Disease Control and Prevention, 2020). In fact, when mass testing has occurred in prisons, preliminary evidence has indicated that a majority of cases identified are pre-symptomatic or a-symptomatic, underscoring the importance of robust and widespread testing efforts (So \& Smith, 2020). Not to be overlooked is the importance of implementing staff testing strategies as well. States generally do not mandate staff testing and do not require staff to report test results. This likely results in many COVID-19 cases being missed among the people most likely to bring COVID-19 into prisons given their daily travel between the correctional setting and community. Staff too, then, should be incorporated into the long-term testing plans of prisons to optimize their COVID-19 prevention strategies.

Underlying this conversation is the need for updated, public information on COVID spread within our country's prisons. This includes integrating data on COVIDrelated policies in prisons and their surrounding communities, keeping Departments of Corrections accountable by mapping their testing strategies to actual testing, and measuring the impact of decarceration, where it does occur, on COVID spread. As the pandemic of COVID persists, it is increasingly crucial that we collect and analyze these data to ultimately flatten the COVID-19 curve in prisons.

\section{Limitations}

One limitation of this analysis is that the prison population is demographically distinct from that of the general population. We do not present standardized estimates because this information is not available at the state level (i.e., COVID-19 deaths by age, sex, and race) and the data which is available is likely systematically biased due to COVID-19 releases, which prioritize high risk populations. Prison populations have a higher percentage of Black inmates than there are Black Americans in the general population (Garcia \& Sharif, 2015). While 13\% of the US population is Black, $33 \%$ of inmates are (Gramlich, 2020; United States Census Bureau, 2020). Prisons also have a much smaller percentage of females (7\%) than in the general population (51\%), and a smaller percentage over the age of $65(3 \%)$ than in the general population (17\%) (Bureau of Justice Statistics, 2020; United States Census Bureau, 2020). Additionally, the most recent publication of Puerto Rico's prison population is from 2012 and may have changed since this date. Lastly, the data available for this analysis is publicly reported by prison systems. Accuracy of reporting and real-time reporting were outside the control of the research team. 


\section{Conclusion}

The intertwining nature of the system of mass incarceration and the COVID-19 pandemic cannot be ignored. This study found that, during the early stages of the pandemic, testing and case rates vary widely from state to state, but, overall, more testing leads to more case identification. To accurately assess COVID-19's impact in US prisons, it is urgently important to implement longterm testing strategies and prioritize other proven mitigation strategies such as reduction of population. It is only through implementing these strategies and continually documenting COVID testing, cases, and fatalities that we will know the spread of COVID in our prison and the injustices it has created and perpetuated.

\section{Acknowledgements}

We are grateful to the entire COVID Prison Project team.

\section{Authors' contributions}

KN and LBR conceptualized and designed this work. KL and EM performed analyses and interpreted data. All authors drafted and revised the manuscript and approved the submitted version.

\section{Funding}

This work was supported by the Jacob and Valeria Langeloth Foundation.

\section{Availability of data and materials}

The datasets generated and/or analyzed during the current study related to prison COVID data are available in the COVID Prison Project repository, https://covidprisonproject.com. Datasets relate generated and/or analyzed during the current study related to the prison's population are available at the Vera Institute of Justice. Datasets relate generated and/or analyzed during the current study related to the general population and COVID are available at the Johns Hopkins Coronavirus Resource Center. Datasets relate generated and/or analyzed during the current study related to the general population are available at the US Census Bureau.

Ethics approval and consent to participate

Not applicable. This paper uses publicly available data only.

\section{Consent for publication}

Not applicable.

\section{Competing interests}

The authors declare that they have no competing interests.

\section{Author details}

'Department of Epidemiology, Gillings School of Global Public Health, University of North Carolina at Chapel Hill, Chapel Hill, USA. ²Department of Sociology, Department of Policy Analysis and Management, Cornell University, 323 Uris Hall, Ithaca, New York 14853, USA. ${ }^{3}$ Department of Sociology, University of Miami, 5202 University Drive Merrick Building, Rm 120, Coral Gables, FL 33124, USA. ${ }^{4}$ Center for Health Equity Research, University of North Carolina at Chapel Hill, 333 S. Columbia Street, Chapel Hill, NC 27559, USA. ${ }^{5}$ Department of Social Medicine, University of North Carolina at Chapel Hill, 333 S. Columbia Street, Chapel Hill, NC 27559, USA.

Received: 24 August 2020 Accepted: 9 November 2020

Published online: 11 December 2020

\section{References}

Akiyama, M. J., Spaulding, A. C., \& Rich, J. D. (2020). Flattening the curve for incarcerated populations - Covid-19 in jails and prisons. The New England Journal of Medicine, 382, 2075-2077.

Bureau of Justice Statistics. Territories. 2012. https://www.bjs.gov/index.cfm?ty= tp\&tid=144 (Accessed 15 Jul 2020)

Bureau of Justice Statistics. Prisoners in 2018. 2020.
Garcia, J. J.-L., \& Sharif, M. Z. (2015). Black lives matter: A commentary on racism and public health. American Journal of Public Health, 105, E27-E30.

Gould E, Shierholz H. Not everybody can work from home. Economic Policy Institute, Working Economics Blog. 2020.

Gramlich, J. (2020). Black imprisonment rate in the U.S. has fallen by a third since 2006. Washingon D.C.: Pew Research Center.

Johns Hopkins University. Coronavirus Resource Center. 2020. https://coronavirus. jhu.edu (Accessed 15 Jul 2020).

Laurencin, C. T., \& McClinton, A. (2020). The COVID-19 pandemic: A call to action to identify and address racial and ethnic disparities. Journal of Racial and Ethnic Health Disparities, 7, 398-402.

Link, B., \& Phelan, J. (1995). Social conditions as fundamental causes of disease. Journal of Health and Social Behavior, 80-94.

Nowotny, K., Bailey, Z., Omori, M., \& Brinkley-Rubinstein, L. (2020). COVID-19 exposes need for progressive criminal justice reform. American Journal of Public Health, 110, 967-968.

Phelan, J. C., \& Link, B. G. (2015). Is racism a fundamental cause of inequalities in health? Annual Review of Sociology, 41, 311-330.

Saloner B, Parish K, Ward JA, DiLaura G, Dolovich S. COVID-19 cases and deaths in federal and state prisons. JAMA 2020; published online July 8. DOl:https://doi. org/10.1001/jama.2020.12528.

So, L., \& Smith, G. (2020). In four U.S. state prisons, nearly 3,300 inmates test positive for coronavirus -- $96 \%$ without symptoms. Reuters https://www.reuters.com/ article/us-health-coronavirus-prisons-testing-in/in-four-u-s-state-prisonsnearly-3300-inmates-test-positive-for-coronavirus-96-without-symptomsidUSKCN2270RX (Accessed 9 Oct 2020).

The Atlantic. The COVID tracking project. 2020.

The Centers for Disease Control and Prevention. Interim considerations for SARSCoV-2 testing in correctional and detention facilities. 2020.

The COVID Prison Project. 2020. https://covidprisonproject.com (Accessed 15 Jul 2020).

The Marshall Project. A State-by-State Look at Coronavirus in Prisons. The Marshall Project. 2020.

United States Census Bureau. 2019 National and State Population Estimates. 2019.

United States Census Bureau. QuickFacts United States. 2020. https://www.census. gov/quickfacts/fact/table/US/PST045219 (Accessed 15 Jul 2020).

United States Immigration and Customs Enforcement. Detention management. 2020.

Vera Institute of Justice. People in Prison 2019. 2020.

Wagner P, Bertram W. 'What percent of the U.S. is incarcerated?' (And other ways to measure mass incarceration). Prison Policy Initiative. 2020.

Widra E, Hayre D. Failing grades: States' responses to COVID-19 in Jails \& Prisons. Prison Policy Initiative. 2020.

Widra E, Wagner P. While jails drastically cut populations, state prisons have released almost no one. Prison Policy Initiative.2020.

World Health Organization. COVID-19 Virtual Press Conference. 2020.

\section{Publisher's Note}

Springer Nature remains neutral with regard to jurisdictional claims in published maps and institutional affiliations.

Ready to submit your research? Choose BMC and benefit from

- fast, convenient online submission

- thorough peer review by experienced researchers in your field

- rapid publication on acceptance

- support for research data, including large and complex data types

- gold Open Access which fosters wider collaboration and increased citations

- maximum visibility for your research: over $100 \mathrm{M}$ website views per year

At $\mathrm{BMC}$, research is always in progress.

Learn more biomedcentral.com/submission 